\title{
Guía Didáctica para la implementación de los Objetivos de Desarrollo Sostenible en Educación Primaria
}

\author{
Ma del Rosario Mendoza Carretero \\ Departamento de Estudios Educativos. Universidad Complutense de Madrid. España. \\ mamendoz@ucm.es \\ ORCID: https://orcid.org/0000-0002-6924-3196
}

[Recibido: 10 enero 2022. Revisado: 20 enero 2022. Aceptado: 24 enero 2022]

Para citar la obra reseñada: Mendoza Carretero, M.R. (2021). Reseña de Sáenz-Rico, B. (Coord.) (2021). Guía Didáctica para la implementación de los objetivos de Desarrollo Sostenible en Educación Primaria. 320 págs. ISBN 978-84-09-17608-3. Revista de Educación Ambiental y Sostenibilidad 3(2), 2401. doi: 10.25267/Rev_educ_ambient_sostenibilidad.2021.v3.i2.2401

En 2015, la Asamblea General aprueba, mediante el documento "Transformar nuestro mundo: la Agenda 2030 para el Desarrollo Sostenible”, la Agenda 2030. Esta, que se compone de 17 Objetivos de Desarrollo Sostenible (ODS) y 169 metas, tiene como propósito garantizar un futuro mejor para todos, siendo necesario desarrollar acciones en favor de las personas, el planeta y la prosperidad.

Sin embargo, según lo reportado en el Informe de los Objetivos de Desarrollo Sostenible (2021), la comunidad mundial se encuentra en un momento crítico para alcanzar los ODS y esto no se debe únicamente a la crisis actual producida por la COVID-19, la cual ha exacerbado las desigualdades, pues pese a los avances producidos en algunos ODS (por ejemplo: reducción de la pobreza, salud maternoinfantil...), otros se quedaron rezagados o se estancaron (por ejemplo: reducción de la desigualdad, lucha contra el hambre...).

Europe Sustainable Development Report 2021 informa que, en la actualidad, España necesita desempeñar acciones que mejoren la consecución de los ODS para el 2030 (SDG Rank 22/34) y así no dejar a nadie atrás. Esta mejora tiene que producirse a través de diversos ámbitos, pero, sin duda, la educación es un instrumento clave que se debe emplear, pues esta supone una oportunidad de cambio y transformación para la sociedad.

Una ciudadanía formada, informada e implicada es capaz tomar decisiones fundamentadas y actuar de forma responsable, individual o colectivamente, para tratar de asegurar un futuro factible desde el punto de vista ecológico y económico, tanto para las generaciones actuales como futuras. Por lo que el material que se presenta, bajo la denominación "Guía Didáctica para la implementación de los Objetivos de Desarrollo Sostenible (ODS)”, puede contribuir a lograr este cambio.

Este documento se ha diseñado como un recurso para guiar a los profesionales de la Educación Primaria en la introducción, en el desarrollo y anclaje de los ODS en esta etapa educativa, teniendo en cuenta que el profesorado, mediante su práctica 
educativa, es promotor del cambio y agente transformador del alumnado mediante la sostenibilización curricular.

Esta guía se estructura en dos partes. La primera de ellas responde a cuestiones como: ¿qué son los ODS?, ¿cómo puede la Guía ayudar a que tu práctica docente sea más sostenible? y ¿cómo trabajar con la Guía desde el Currículum de Educación Primaria? La segunda parte se centra en el desarrollo curricular y está compuesta por 17 unidades, correspondiéndose cada una de ellas con un ODS. Estas unidades siguen el currículo básico de la Educación Primaria (contenidos, criterios de evaluación y estándares de aprendizaje), publicado en el Real Decreto 126/2014, de 28 de febrero, y las competencias para el desarrollo sostenible propuestas por la UNESCO (análisis crítico, reflexión sistémica, toma de decisiones colaborativa y sentido de responsabilidad hacia las generaciones presentes y futuras).

Por último, es preciso mencionar que este documento es uno de los resultados alcanzados dentro del proyecto Inclusión 2030. Acciones formativas transformadoras desde un enfoque interseccional, integrado por Personal Docente Investigador (PDI) e investigadores en formación, y ha sido financiado en la XV Convocatoria de ayudas a proyectos de Cooperación al Desarrollo Sostenible de la Universidad Complutense de Madrid. 